IRA-International Journal of Education \&

Multidisciplinary Studies

QUARTERLY

ISSN 2455-2526; Vol.16, Issue 03 (July-Sep, 2020)

Pg. no. 189-193.

Institute of Research Advances

https://research-advances.org/index.php/IJEMS

IIRA

\title{
Cultivating Intercultural Awareness amongst Elementary and Secondary School Students through Experiential Learning- A Review
}

Xiaochun Wu

School of Foreign Studies, Yangtze University, Hubei, 434023 PRC China.

Type of Work: Peer-Reviewed

DOl: http://dx.doi.org/10.21013/jems.v16.n3.p8

\section{How to cite this paper:}

Xiaochun Wu (2020). Cultivating Intercultural Awareness amongst Elementary and Secondary School Students through Experiential Learning- A Review. IRA International Journal of Education and Multidisciplinary Studies (ISSN 2455-2526), 16(3), 189-193. DOI:

http://dx.doi.org/10.21013/jems.v16.n3.p8

(c) Institute of Research Advances.

This work is licensed under a Creative Commons Attribution-NonCommercial 4.0 International License subject to a proper citation to the publication source of the work.

Disclaimer: The scholarly papers as reviewed and published by the Institute of Research Advances (IRA) are the views and opinions of their respective authors and are not the views or opinions of the IRA. The IRA disclaims of any harm or loss caused due to the published content to any party.

Institute of Research Advances is an institutional publisher member of Publishers International Linking Association Inc. (PILA-CrossRef), USA. The institute is an institutional signatory to the Budapest Open Access Initiative, Hungary advocating the open-access of scientific and scholarly knowledge. The Institute is a registered content provider under Open Access Initiative Protocol for Metadata Harvesting (OAI-PMH).

The journal is indexed \& included in WorldCat Discovery Service (USA), CrossRef Metadata Search (USA), WorldCat (USA), OCLC (USA), Open J-Gate (India), EZB (Germany) Scilit (Switzerland), Airiti (China), Bielefeld Academic Search Engine (BASE) of Bielefeld University, Germany, PKP Index of Simon Fraser University, Canada. 


\begin{abstract}
This paper systematically reviews the studies on the cultivation of intercultural awareness of elementary and secondary school students through experiential teaching. The article analyzes the studies regarding topics like content-based and task-based research as well as student, teacher and environment factor, pointing out achievements and design limitations in the current studies hoping to help researchers in the future, followed by implications for pedagogy.
\end{abstract}

Key words: intercultural awareness, experiential learning, elementary \& secondary language teaching, literature review

\title{
1. Background
}

Expressions like 'I do and I understand' from Confucius and so forth have demonstrated the vital role of experience in learning. Kolb suggests that experiential learning is 'an active pedagogy emphasizing concrete experience and abstract conceptualization' (1984, cited from Scogin et al., 2017). While Sonja Knutson (2003:53) holds the view that 'experiential learning as a philosophy is based on the ideals of active and reflective learning, building on previous learning experiences and requiring the personal involvement of the learner'. According to Shirts (1995), a simulated cross-cultural experience would motivate participants to learn how to act in any culture and to further realize differences among various cultures. 'Successful approaches to elementary school foreign language classes emphasize concrete experiences and good use of visuals and physical activity'(Curtain \& Helena, 1991:327). Yet as imperative as it is, there are many obstacles when combining experiential learning with language teaching. The following overview of literature aims to familiarize readers with the body of the cultivation of intercultural awareness in elementary and secondary school students taught through experiential learning in language teaching. Topics addressed include content-based and task-based researches as well as student, teacher and environment factor. The overview points out achievements and design limitations in the current studies hoping to help researchers in the future, followed by implications for pedagogy.

\section{The Overview of Studies}

\subsection{Content-based Experiential Learning}

Content-based Research is ranked the first here because cultural activities are based on the content. Defined by Lyster and Ballinger (2011: 279, cited from Moeller, 1994), content-based language teaching (CBLT) is 'an instructional approach in which non-linguistic curricular content such as geography or science is taught to students through the medium of language that they are concurrently learning as an additional language'. Moeller (1994:8) says in his article, 'when learning the word to 'dance', a painting by Degas can serve as the medium, or the word for "chair" might be illustrated through Van Gogh's painting'. For the development of intercultural awareness, a lot of materials related to cultures can be used, textbook, video, radio, pictures etc. Materials for content are easy to access. However, teachers need to spend energy and time on finding suitable materials for students and think carefully about how to make full use of them. Among the studies, interdisciplinary design and local culture also need to be taken into consideration, such as the holistic analysis of the National Association of Secondary School Principals (NASSP) from Moeller (1994). According to Curtain \& Helena (1991), these should be predictable or familiar to the children from their native culture. Still more details are needed about how to implement in and outside the classroom, how to choose materials suitable for elementary and secondary schools.

\subsection{Task-based Experiential Learning}

Task is the core of experiential learning for the development of intercultural awareness. According to Mohan, there exist two types of activities in the content-based classroom: "expository" and "experiential." Expository activities include classroom discussions and lectures; experiential activities include role-plays, simulations, demonstrations, field trips, and interactive activities designed to emulate real world activities (Mohan, 1986; cited from Moeller, 1994). To conclude, tasks mainly include game, drama, role play, discussions, demonstrations, lecture etc. 
Above all, games are used easier and more frequently in cultural trainings and language classes such as BaFa BaFa (Ong-Flaherty C. et al. 2017), Barnga, Ecotonos and Markhall. Drama, similar to games, seems an ideal medium to provide necessitates experience of a wide range of communicative contexts, relationships and modes (Rothwell, 2011). In her research in 2011, students' voice tells that learners' commitment to immerse themselves bodily and verbally in role and to take an active interest in the new cultural contexts are essential steps towards understanding cultural difference.

Some details, however, need to be thought and measured carefully: limited proficiency of the learners; pre-test if necessary; variation existed; control group if imperative; how games can be better designed under the limited time, space, student numbers in a task; what exact available tasks for developing places which don't have so many facilitations; and last but not least, how to measure more scientifically. One fact is that the theory and practice are not closely related, which should be taken into consideration.

\subsection{Student Factor}

Student-centered task design rather than teacher-centered gradually becomes the trend of modern teaching. We need to care about students because 'all learning experiences are personal and unique to us'(Beard \& Wilson, 2014). Within FL culture learning, instances of sensitivity, respectfulness, openmindedness to the 'other' or 'awareness of difference and diversity' are also important factors to consider (Garau \& Jacob, 2015).

Are there cultural differences in learning style? In order to tackle this question, Joy and Kolb(2009)demonstrated that educators have to ensure that the learning situations they design have elements that the students from different cultures can comprehend. Here, the study gives us some new dimensions for research-a more representative area, variables known to shape learning styles such as the types of personality and the current work context, particularly in elementary and secondary schools. As for personalities, Van \& Oudenhoven (2013) analyzes its influence based on the framework of ABC - affect, behavior and cognition. They argued that students with social-perceptual traits (social initiative, open-mindedness) may facilitate cultural learning, perceive its challenging aspects and respond with positive affect. These theories would be better understood if combined with the practices.

During experiential classes, students would suffer “cultural shock' more or less, for which the consideration for cognitive and affective factors is necessary, especially in a dynamic experiential learning. The consideration for cognitive and affective factors paves a way for better development of the intercultural awareness. Affective factors, "those that deal with emotional reactions and motivations of the learner" (Scovel, 1991, cited from Moeller, 1994:542), can be addressed through the integration of a variety of teaching approaches aimed at reducing anxiety and tension.

In addition to personal factors, Blohm (2005, cited from Silberman, 2009) points out the cooperation as one of the possible factors that carry cultural implications. The uniqueness of everybody brings more cultural differences, an exact experiential learning method. In a word, we ought to think about the different learning styles, personalities, cognitive factor, affective factor, etc. and the cooperation among students for the cultivation of intercultural awareness through experiential learning.

\subsection{Teacher Factor}

Even in the student-centered environment, active teacher involvement in intercultural project is necessary for student success. Angene (1986) says that as the teaching as a cross-cultural encounter rationale is usually limited to the classroom, the self-development rationale usually looks at the teacher apart from the classroom. Something needs to bring the two together. Whereas active teacher involvement requires teachers to have a sense of cultural awareness and to be able to design classes (Zhang, 2007). Teachers reflect that developing students' culture awareness through EL causes a lot of problems like time. A survey of 210 foreign language teachers on cultural teaching conducted by Zena Moore in the USA in 1996, however, argued that most teachers with rich teaching experience and cultural training can overcome the difficulties of limited time (Zhang, 2007). Thus researches for preservice teacher education and training during teaching are both critical (Zhang, 2007). At the moment, 
some studies mainly focus on the teachers' experiential learning abroad (Angene, 1986), which is not an ideal method in countries like China. Here, we can also have some guidance for the coming researches-more are needed for teachers how to better instruct students' experiential teaching skills.

\subsection{Environment Factor}

Finally, the environment has a long-term effect on the development of intercultural awareness through experiential learning. Joyce Epstein, a middle school researcher, emphasized that "responsive environments that provide students with care and support, as well as challenging programs that will increase their learning" must be provided for middle school students(1990, cited from Moeller, 1994). Environment-based researches can include researches about the national education environment, school and classroom, CALL (Computer Assisted Language Learning environment)/online teaching, telecollaborative exchanges, local community, abroad, private spaces and so on.

Above all, 'teach to a test' has a strong influence for the development of culture awareness through experiential learning, even in the US (Scogin \& Kruger, 2017). Scogin \& Kruger did an investigation of a middle school experiential learning and found that students in the experiential program progressed appropriately on standardized tests and did not differ significantly from their counterparts in traditional classes. The thing to do is to find out how to combine the experiential learning appropriately with the culture awareness and language learning under this background. But the research also needs more evidence to convince the result of the reading scores in this study. Besides, teachers can use a lot of tools to create an atmosphere for culture awareness through experiential learning like posters, cards, pictures.

The CALL or online teaching keeps pace with the development of Internet. There are also telecollaborative exchanges. Gascoigne and Parnell (2014) found that under telecollaborative exchanges students have more interest in the language(cited from Moreno et. al, 2017). Belz's study(2002) on the social aspect of German-American telecollaboration found that even though participants in one group may position themselves as "less competent" members based on their own perception of proficiency, the bilingual social interaction helped students feel more comfortable using technology for learning and find support from their foreign peers(cited from Moreno, et. al, 2017).

Besides public places, students also need private spaces for the effects of experiential learning for culture awareness. Here involves the definition of reflection. The reflection requires learners to engage actively with their own past acquisition experiences and focuses them on the future. Reflection usually requires access to private thinking space, something which is well known by the outdoor learning profession (Beard \& Wilson, 2014). Educators should think about the private spaces to achieve a better reflection for students in the experiential learning.

From the field of environment of development cultural awareness through experiential learning, the following problems are in need to be settled down:1) How to overcome the obstacle of open environments where students feel that no one watch them so that they have freedom?2) How to increase learners' ownership and responsibility for their own learning? 3) When students have grade focus, what is the teaching standard in this field?

\section{Conclusion}

The overview from five aspects points out the research value and design limitations as well as further needs in the current researches, followed by implications for pedagogy. Researchers should consider these design precautions common to much of the existing research: adequate descriptions of the research procedures in order to open the methods not only to evaluation and critique but to replication; the control of other variables; the pre-test and control group if it could help better certify the results; the better way to measure the effectiveness of different measures for cultivating students' intercultural awareness through experiential learning.

From five perspectives, we see that based on the content of culture, teachers organize various tasks according to the different factors like students and environment, thus creating a whole process of experiential learning. That, how to combine the theory with practice more relevantly is a problem 
according to the above analysis. Regrettably, developing intercultural awareness in language teaching through experiential learning is more prevalent in western countries. Researches carried out in specific measures, for specific groups, in specific areas are still in need.

\section{References}

[1]. Beard C. \& J. P. Wilson. Experiential learning: A handbook for education, training and coaching[M]. Kogan Page Publishers, 2013.

[2]. Curtain H. A. Methods in Elementary School Foreign Language Teaching[J]. Foreign Language Annals, 2008, 24(4):323-329.

[3]. Joy S. \& D. A. Kolb. Are there cultural differences in learning style?[J]. International Journal of intercultural relations, 2009, 33(1): 69-85.

[4]. Juan-Garau M. \& K. Jacob. Developing English learners' transcultural skills through content-and taskbased lessons[J]. System, 2015, 54: 55-68.

[5]. Knutson S. Experiential learning in second-language classrooms[J]. TESL Canada Journal, 2003: 52-64.

[6]. Moeller A. J. Content-Based Foreign Language Instruction In the Middle School: An Experiential Learning Approach[J]. Foreign Language Annals, 1994, 27(4):535-544.

[7]. Moreno-López, Isabel, Ramos-Sellman A., Miranda-Aldaco C., et al. Transforming Ways of Enhancing Foreign Language Acquisition in the Spanish Classroom: Experiential Learning Approaches[J]. Foreign Language Annals, 2017, 50(2):398-409.

[8]. Ong-Flaherty C., Valencia-Garcia D., Martinez D. A., et al. Effectiveness of gaming in creating cultural awareness[J]. Learning, Culture and Social Interaction, 2017, 12:149-158.

[9]. Rothwell J. Bodies and language: Process drama and intercultural language learning in a beginner language classroom[J]. Research in Drama Education: The Journal of Applied Theatre and Performance, 2011, 16(4): 575-594.

[10]. Scogin S. C., Kruger C. J., Jekkals R. E., et al. Learning by experience in a standardized testing culture: Investigation of a middle school experiential learning program $[\mathrm{J}]$. Journal of Experiential Education, 2017, 40(1): 39-57.

[11]. Shirts R. G. Beyond ethnocentrism: Promoting cross-cultural understanding with $\mathrm{BaFa} \mathrm{BaFa}[\mathrm{A}]$. In Fowler S. M. \& M. G. Mumford (Eds.), Intercultural sourcebook: Cross-cultural training methods. Volume 1[C]. Yarmouth, ME: Intercultural Press, 1995.

[12]. Silberman M. I. The handbook of experiential learning[M].John Wiley \& Sons, 2009.

[13]. Van der Zee K. \&J. P.Van Oudenhoven. Culture shock or challenge? The role of personality as a determinant of intercultural competence[J]. Journal of Cross-Cultural Psychology, 2013, 44(6): 928-940.

[14]. Wilson \& Angene H. Cross-cultural experiential learning for teachers[J]. Theory Into Practice, 1986, 26:519-527.

[15]. Zhang Hongling. Intercultural Approach to Foreign Language Teaching[M].Shanghi Foreign Language Education Press, 2007. 